\title{
La gènesi dels somatismes: accions humanes fossilitzades
}

\author{
The origin of somatisms: frozen human actions
}

\author{
Elena Sánchez-López \\ Universitat d'Alacant \\ elena.sanchez@ua.es
}

\begin{abstract}
Somatic idioms - those including a part of the body - have been traditionally studied from a synchronic perspective, yielding different explanations for their semantic value. The main objective of this paper is to highlight the diachronic origin of idiomatic meaning, by illustrating the process of phraseologization from a historical, usage-based perspective. As the first step, we will reflect on the general nature of phraseological meaning, and then on the semantic particularities of somatic idioms. Secondly, we will carry out a corpus-based diachronic analysis of the Catalan idiom tapar-se el nas (to hold one's nose) within the framework of the Invited Inference Theory of Semantic Change. The different stages of the process will be exemplified and discussed. As a result, a new notion of somatic idioms as frozen human actions will be presented.
\end{abstract}

Keywords: somatic idioms, phraseologization, usage-based, corpus linguistics, inferences

\section{INTRODUCCIÓ}

La fraseologia és, en essència, un relicte del passat inserit en el discurs present. Si partim d'aquesta base, les locucions somàtiques, les que compten amb el nom d'una part del cos entre els seus components, són accions i característiques humanes (gestos, moviments, trets físics) fossilitzades. Aquesta mena de locucions han estat sovint tractades com a unitats transparents, ja que són fàcils de motivar perquè reflecteixen 
accions que poden ser universals. Malgrat això, hem de ser conscients que van estar fixades en un temps passat i que el procés de fraseologització que les va generar ha configurat el seu significat $\mathrm{i}$ ús present. En aquest procés influeixen fenòmens cognitius, discursius i culturals.

En els estudis fraseològics, s'ha parat molta atenció a la comparació interlingüística i a l'aportació semàntica que fan els lexemes somàtics a les locucions de què formen part. Des d'una perspectiva sincrònica i cognitiva, s'han formulat teories sobre els processos metafòrics i metonímics que han portat a l'adquisició d'idiomaticitat. En canvi, l'elaboració discursiva i cultural que ha portat a l'adquisició del significat no-composicional de les locucions no ha estat gairebé estudiada. Al llarg del present article, pararem atenció a aquest procés de gènesi de les locucions somàtiques des de la lingüística basada en l'ús, aplicant els principis de la lingüística cognitiva amb la metodologia de la lingüística de corpus ${ }^{1}$. Encetarem l'article amb una reflexió sobre el significat fraseològic en general. Posteriorment, ens centrarem en les peculiaritats semàntiques dels somatismes. El nucli del nostre treball serà una anàlisi diacrònica de la locució tapar-se el nas en el CIGCA (Corpus Informatitzat de la Gramàtica del Català Antic), el CIGCAMOD (Corpus Informatitzat de la Gramàtica del Català Modern) i el CTILC (Corpus textual informatitzat de la llengua catalana), que tindrà com a objectiu observar-ne l'evolució, aplicant les teories actuals sobre canvi semàntic.

\section{EL SIGNIFICAT FRASEOLÒGIC}

L'estadi actual d'una llengua és el resultat final d'un procés evolutiu al llarg del temps, és a dir, d'un procés diacrònic. Aquesta afirmació és aplicable a tots els elements lingüístics, però, en general, no sol ser evident per als parlants. Com a usuaris de la llengua, fem servir les paraules monolèxiques amb el significat actual que coneixem, en els contextos que hem aprés, però no ens parem a reflexionar què significaven en el s. XV o com van evolucionar a partir del llatí. Tampoc solem fer atenció a tots els significats que poden associar-se a una forma abans d'emprar-la en una oració. En canvi, la nostra actitud cap a les unitats fraseològiques és quelcom diferent. El fet que es tracte d'unitats polilèxiques assenyala cap al seu punt de partida: la combinació lliure de paraules que les va originar. En molts casos, aquesta combinació lliure de paraules encara està vigent, de manera que ens trobem amb una polisèmia evident. Reconeixem una cadena de paraules amb dos significats ben diferenciats: el composicional i el fraseològic. El composicional s'entén a partir de la suma dels significats dels components. En canvi, el fraseològic s'ha de conèixer. Aquesta disparitat ha estat sovint identificada com a idiomaticitat o sentit figurat.

\footnotetext{
${ }^{1}$ Els principis teòrics que regeixen aquesta mena d'estudi es detallen en Sánchez-López (en premsa).
} 
La percepció de la idiomaticitat com a sentit figurat està provocada pel procés de motivació que, segons Piirainen (2012), és el procés cognitiu mitjançant el qual els parlants poden "activar determinades estructures cognitives per entendre l'ús d'una expressió idiomàtica concreta i el significat que se li atribueix convencionalment. La relació entre els dos nivells conceptuals, entre la imatge mental que evoca l'estructura lèxica i el llenguatge figurat, es fa [així] comprensible per a ells" (p. 48). De manera que el parlant, quan posa en relació el significat fraseològic amb el composicional, crea una imatge que es relaciona amb la figurativitat. És important destacar que la motivació inicial o etimològica no ha de coincidir amb les posteriors motivacions que en facen els parlants. De fet, quan la motivació inicial no és reconeguda per la comunitat, la unitat fraseològica es desmotiva i la tendència dels parlants serà remotivar-la, cosa que pot dur al canvi fraseològic (vegeu Sánchez-López, 2015). En el cas que els dos significats s'hagen allunyat tant que la motivació no siga possible, la unitat fraseològica es considerarà opaca, fossilitzada o "frozen". Per altra banda, un parlant no haurà de fer el procés de motivació per a poder utilitzar una unitat fraseològica, ja que aprendrà la unitat amb el significat fraseològic.

Els manuals tradicionals de fraseologia han inclòs la "idiomaticitat" (Corpas, 1996; Ruiz Gurillo, 1997; Burger, 1998; Conca \& Guia, 2014) entre els trets definitoris de les unitats fraseològiques. A pesar de la centralitat del terme, no arriben a copsar-ne l'abast, ja que es limiten a adoptar una perspectiva sincrònica. Per a entendre què és aquesta "idiomaticitat" i com sorgeix, s'ha d'estudiar la fraseologia des d'una perspectiva diacrònica (vegeu Sánchez-López, 2020). El canvi de mirada ens permet observar els processos de fraseologització i canvi fraseològic. La fraseologització es produeix quan una combinació lliure de paraules adquireix un significant conjunt, és a dir, quan un significat que anteriorment depenia del context es convencionalitza (vegeu Sánchez-López, 2015; Timofeeva, 2012, 2016). El nou significat tan sols s'activa quan les paraules apareixen juntes, fet que tradicionalment s'ha entès en termes de fixació, i no es pot deduir de la suma del significat dels components, que s'identifica amb la idiomatització. Des de la nova perspectiva preferim parlar d'una fixació formal, semàntica i pragmàtica. El canvi de mirada no es limita a fer una fraseologia de recuperació i recol-lecció d'exemples del passat, sinó que inclou l'evolució al llarg del temps i els mecanismes que la provoquen.

En aquest sentit, subscrivim la definició de Timofeeva (2016, p. 680):

Una locución es una agrupación de palabras que funciona semántica y discursivamente como un lexema. Las palabras que forman la locución no actúan de un modo independiente, sino que todas juntas originan un significado holístico global. Las locuciones son un tipo de unidades fraseológicas y conforman el objeto de estudio de la fraseología. Desde el punto de vista diacrónico, las locuciones se presentan como resultado de un proceso evolutivo en el que un sintagma experimenta la progresiva convencionalización de los valores inferenciales inicialmente dependientes del contexto que pasan a formar parte de su semántica. 


\section{EL SIGNIFICAT FRASEOLÒGIC DELS SOMATISMES}

El somatismes són unitats fraseològiques que inclouen el nom d'una part del cos entre els seus components i que presenten un significat fraseològic lligat als comportaments, costums i aptituds humans. Dins de la taxonomia fraseològica, es tracta d'una categoria de caire semàntic, ja que es crea atenent al significat d'un dels constituents. El seu interès rau en el fet que són un fenomen universal que està present en totes les llengües. A més, és molt freqüent tant pel que fa al percentatge que representa dins del conjunt de les unitats fraseològiques d'una llengua, com pel que fa al seu ús. Aquesta preeminència fa que els investigadors els paren especial atenció. Alguns autors apunten que l'universalisme està originat pel caràcter antropocèntric de la fraseologia, "ya que la mayoría de los fraseologismos con sustantivos somáticos se aplica sólo al ser humano: comportamientos, costumbres, aptitudes..." (Čermak, 2000, p. 56-58, citat per García-Page, 2008, p. 363). La lingüística cognitiva ens revela que l'antropocentrisme que explica la profusió d'aquestes unitats fraseològiques és aplicable a la llengua en general i està provocat per la corporeïtzació (embodiment, embodied mind; Lakoff \& Johnson, 1999; Clark, 2008; Rubert, 2009; Shapiro, 2011), el fet que la ment humana estiga inevitablement lligada a la percepció i a l'experiència corporal, cosa que es reflecteix en la conceptualització i l'expressió lingüística.

La lingüística cognitiva ha demostrat que la corporeïtzació juga un paper molt important en la construcció del significat. Però no es limita a la vivència del cos o a l'objectivització de fenòmens externs, sinó que està passada pel sedàs de la cultura. Com assenyala Martines (2021, p. 267-268), “el símbol lingüístic connecta amb els conceptes l'elaboració dels quals és resultat de l'experiència humana $i$, cosa no menys important, del processament que n'ha fet cada societat". En relació amb la importància de la cultura en la conceptualització, Martines (2020, p. 326) cita l'estudi clàssic de Geeraerts \& Grondelaers (1995) sobre l'expressió de la ira, on es remarca que les metàfores emprades (foc, pressió, vermellor) poden estar basades en l'experiència corporal, però que "connecten amb la concepció del cos de la medicina vinculada amb la teoria dels humors, influent en la ciència i en la cultura durant molts segles, fins a la generalització del mètode científic".

Junt amb els criteris de freqüència i d'universalitat que comentàvem adés, els somatismes han despertat l'interès dels investigadors pel seu comportament discursiu i la vinculació amb la realitat que representen. Aquesta vinculació, que ve marcada per la relació entre el significat composicional i el fraseològic, ha rebut tradicionalment un tractament sincrònic. Des d'aquesta perspectiva, Burger (2010) afig a la caracterització general el fet que conceptualitzen i codifiquen lingüísticament el comportament no-verbal (p. 47) i destaca que ha de ser un comportament susceptible de fer-se i que ha de tenir un significat cultural codificat (p. 64).

Atenent a aquests paràmetres, proposa una anàlisi semiòtica que inclou les capes següents: 
1. l'acció fàctica (la "forma" del comportament no-verbal)

2. el significat convencional associat a l'acció (el "significat" del comportament no-verbal)

3. l'enunciat lingüístic (la "forma" de l'enunciat)

4. el "significat" doble de l'enunciat lingüístic:

4.a) la denominació de l'acció fàctica $(=1)$

4.b) la denominació del significat de l'acció $(=2)$

En relació amb aquestes capes, Burger afirma que els somatismes en sentit estricte són aquelles locucions on tant l'acció fàctica com el valor cultural continuen vigents (com ara tapar-se el nas). Per a aquells que no complisquen aquest requisit, és a dir, que l'acció fàctica ja no siga viva o no es relacione amb el valor cultural (com ara pujar la mosca al nas), introdueix l'etiqueta de pseudosomatisme. Tot i que des d'una perspectiva sincrònica puga semblar una diferenciació rellevant, des d'una perspectiva diacrònica es dilueix sensiblement la diferència, ja que totes les locucions somàtiques han estat motivades inicialment per una acció $\mathrm{i}$ les implicatures (o inferències ${ }^{2}$ ) que comportava.

\section{GÈNESI DE TAPAR-SE EL NAS}

En aquest apartat analitzarem la gènesi de la locució tapar-se el nas, mitjançant l'observació de la seua evolució en els corpus CIGCA, CIGCAMOD i CTILC. Hi destacarem les diverses fases de la fraseologització3: estadi inicial $>$ context pont $>$ context de canvi > convencionalització, així com el posterior canvi fraseològic, a fi d'il'lustrar-ne l'evolució.

\subsection{SIGNIFICAT DE TAPAR-SE EL NAS}

L'experiència del cos a través dels sentits ens diu que: corrupció (putrefacció) > pudor $>$ necessitat de tapar el nas. Quan algú es tapa el nas és perquè nota la pudor, que prové de la corrupció. En l'actualitat, l'ús més habitual del mot corrupció fa referència a les accions d'aquell que actua il·legalment, però el seu origen és més físic, com recull la primera accepció de corrompre en el DIEC2:

\footnotetext{
${ }^{2}$ Mentre que Levinson (2004) les denomina implicatures, tant Heine i Kuteva (2002) com Traugott i Dasher (2002) parlen d'inferències.

${ }^{3}$ Aquestes fases coincideixen amb les que Heine i Kuteva (2002) i Traugott i Dasher (2002) han identificat per a la gramaticalització. En relació amb el procés de fraseologització i canvi fraseològic, en trobareu una descripció teòrica exhaustiva en Sánchez-López $(2015,2020)$.
} 
11 v. tr. [LC] Alterar (una substància) tornant-la putrescent, insana. La calor corromp la carn. Miasmes que corrompen l'aire.

Aquesta alteració que produeix la putrefacció del cos o la carn, agafa un matís més abstracte quan s'aplica a la bondat, la integritat i la puresa, com es reflecteix en la segona accepció del mot:

$21 \mathrm{tr}$. [LC] Alterar la sanitat, la bondat, la integritat, la puresa, (de l'ànima, de la consciència, dels costums). Certes doctrines corrompen els costums. Corrompre el gust del públic. 22 intr. pron. [LC] Costums que s'han corromput.

23 tr. [LC] Desviar (algú) de la rectitud, del deure. Mala gent que corromp els joves. 24 tr. [LC] Induir (algú) a obrar il·legalment, pervertir. Corrompre un jutge amb diners.

En la nostra anàlisi de tapar-se el nas, hem descobert que l'evolució és anàloga.

\subsection{ESTADI INICIAL}

En el s. XIX, trobem un fragment que exemplifica excelsament el model cognitiu ${ }^{4}$ a què ens remet l'expressió, que relaciona la corrupció del cos amb el fàstic i el gest de tapar-se el nas:

L'esfors del malalt fou aquí major que poch ans, peró ni temps tingué de observarho'l baylet, pus, com sorprés de fástich al tocar al llit de son amo, retrocedí en seguida, tapantse'l nas ab los dits, y fent ab la boca, mentres s'en tornava, com quant se está en perill de provocar. ${ }^{5}$ CTILC - La orfaneta de Menargues ó Catalunya agonisant, Antoni de Bofarull (1862).

No es tracta d'una situació aïllada, sinó que es repeteix freqüentment. El fragment següent ens mostra la repetició dels elements clau: cadàver, fàstic i tapar-se el nas:

Quan els apòstols van arribar al cadàver del gos, girant els ulls amb fàstic i tapant-se el nas, van alçar les seves túniques i, un darrera l'altre, van apartar-se de pressa del gos. CTILC - L'edat d'or, Antoni Sabater i Mur (1931).

Una recreació més poètica i intensa de la pudor relacionada amb la corrupció de la carn i el fet de tapar-se el nas ens arriba de la mà de Manuel de Pedrolo:

\footnotetext{
${ }^{4}$ Les categories semàntiques s'emmagatzemen en forma d'imatges (dominis cognitius, Langacker, 1991; models cognitius, Lakoff, 1987; o marcs, Fillmore, 1985) que poden adoptar des de formes molt esquemàtiques (esquemes d'imatge) a representacions més complexes (scripts).

${ }^{5}$ Provocar: perbocar, vomitar.
} 
Són fosques com les primeres i l'olor dolçosa s'hi accentua encara, sembla prendre consistència, liquar-se. Una onada de nàusea li puja per l'estómac, el cap gairebé li roda i ha de repenjar-se contra la paret, on els seus dits sorprenen una substància viscosa que s'esmuny cap a una mena de canal enllacat de sucs espessos. Retira ràpidament la mà $\mathrm{i}$ es tapa el nas amb el faldó de la camisa, però la sentor és insidiosa, penetra el teixit i li pessigolleja la pituïtària. CTILC - Totes les bèsties de càrrega, Manuel de Pedrolo (1967).

Malgrat que entenem que devia usar-se en sentit literal, en els corpus de textos del català antic i modern CIGCA i CIGCAMOD no hem trobat cap testimoni d'una codificació "neutra" de l'acció de tapar-se el nas. Probablement perquè l'esmentada acció no es considerava tant important com per a incloure-la en textos escrits ${ }^{6}$. En canvi, és en l'edat mitjana on trobem els primers contextos pont, aquells contextos específics on es crea una implicatura a favor del nou significat. El significat de la locució ja està present, però depèn del context.

\subsection{CONTEXT PONT}

En el primer testimoni que trobem de la cadena de mots, el lligam entre corrupció física i corrupció moral està ben present. Ja hi apareix el significat més abstracte, però expressat en termes físics, ja que són "la pudor del famer diabolical e les abhominables letgeses e sutzures de tos vicis e màcules vicioses" les que provoquen que els altres es tapen el nas:

Digues, consciència mia, ¿e no has tu gran consolació?, ¿no has singular goig que tota la cort del cel, la qual primerament no $\cdot t$ volia mirar, ans se tapava lo nas, no podent sostenir la pudor del famer diabolical e les abhominables letgeses e sutzures de tos vicis e màcules vicioses, ans giraven la cara e 's tapaven lo nas tots quants són en lo cel, que la dita cort celestial ara mira la tua ballesa que has cobrada". CIGCA - Tractat de confessio, Antoni Canals (1413).

Al llarg d'aquesta obra, és habitual dotar d'olors tant els defectes com les virtuts:

e la dita enveja lo nafra en lo nas per tal que no senta la bona odor de les virtuts, ni de la bona fama. CIGCA - Tractat de confessio, Antoni Canals (1413).

La connexió entre la pudor provocada per la corrupció d'un cos i aquella provocada per la corrupció del caràcter es veu encara més clara en els fragments que presentem a continuació. En un to exemplaritzant:

Un àngel près forma de hom e anave per un camí ab un ermità e sdevench-se que trobaren un hom mort, e l'hermità tapà 's lo nas e dix-li l'àngel: —Què has que t'emboces?

\footnotetext{
${ }^{6}$ Convé recordar el valor que tenien els textos escrits, especialment en l'edat mitjana.
} 
Dix l'ermità: - No pusch sofferir la pudor de aquest hom mort.

E a poch instant veeren venir un jove molt bell sobre un cavall ab sella daurade e ab bells apparellaments. E molt ans que s'encontrassen, l'àngel tapà $\cdot \mathbf{s}$ lo nas, de què·s meravellàs l'ermità e dix a l'àngel: —Què has? Per què·t tapes lo nas?

Respòs 1'àngel: - Cent tants put més aquest jove ergullós e superbiós devant Déus e davant los àngells que 1 cors mort devant los hòmens. CIGCA - Eximplis, diversos autors (s. XV - primera meitat).

En un to humorístic:

que si aygua bevia, luego seria mort, ningú me voldria fer lo sot y quisà ningú tocar volria.

Hi si me sentían pudir de mi ningú faria cas, tots se taparían lo nas, ningú me donaria vi. CIGCAMOD - Comèdia hagiogràfica de Santa Quitèria, anònima (s. XVII).

Com hem vist, en els textos pertanyents al català antic $i$ al català modern trobem l'expressió que codifica l'acció, amb referències explícites al valor cultural. En tots els casos apareix el mot pudor i la font, corrupció del $\cos ^{7}$ d'un mort. De manera que el valor cultural II (significat fraseològic) ja està present en forma d'implicatures generalitzades, però encara no s'ha convencionalitzat, no forma part indestriable de l'expressió.

\subsection{CONTEXT DE CANVI}

En el fragment següent, veurem que encara hi ha la situació real, però que l'element podrit provoca fàstic en la gent que passa, cosa que fa que el protagonista estiga angustiat i amb preocupació:

Passaren uns dies sens adonarsen dels hòstes que ' $\mathrm{n}$ la boljaca tenia, pero notava en tot moment que ' 1 seguia una pudor que no havia aigua florida que li puguera, succés que ' 1 tenia angustiat i ab gran preocupació, per que no veia manera de lliurarse de aquella corrupció que a totes bandes el seguia, i encara se 'n donava de que les gents que per la seua vora passaven tot era tirar ma a taparse els nassos; desesperat el bòn militar per no saber

${ }^{7}$ En el primer fragment, la font de la pudor es la corrupció de la consciència abans d'arribar al cel i prové del "famer diabolical e les abhominables letgeses e sutzures de tos vicis e màcules vicioses", cosa que ens revela com es conceptualitzava la corrupció moral per part de la religió al s. Xv. 
que ferse, cuant al descuit va posar la ma en la boljaca i tota se la empastrá, i era que 'ls homenets, com no s' en recordá de 'lls, s' havien mòrt de fam i, naturalment, al pas dels díes s' havíen podrit. CTILC - Còses de la meua tèrra (la Marina): terça tanda i darrera, Francesc Martínez i Martínez (1947).

En l'exemple següent, els significat fraseològic ja està totalment present $\mathrm{i}$ es presta a un joc de paraules amb el composicional:

— Què voleu que us digui! Això del bestiar fa molta pudor. —El que fa tapar el nas no és pas la bravada dels fems, sinó les 140 pessetes que valen 100 quilos de nitrat. Això si que tapa els esperits. CTILC - L'Urgell: centre de cria i recria ramadera, Rossell i Vilà, Pere Màrtir (1917).

En el darrer exemple d'aquesta fase, ens trobem amb un fragment creatiu, on tapar-nos el nas està utilitzat en sentit fraseològic, però emmarcat en una al·legoria on elements abstractes (blasfèmia, mal parlar, el que es treu per la boca) són acompanyats d'elements pudents concrets utilitzats en sentit figurat, com ara brutícia, femta, sutzures o immundícies. En aquest context, s'activen els dos significats de tapar-se el nas.

Catalans, si verament diem estimar la Pàtria; catalans, si verament volem respectar i qu'hom respecti Catalunya, llencem de la nostra boca la brutícia de la blasfèmia, la llorderia del "cagar-se", la baixesa de tota mena de mal parlar. Catalans, posem-hi esment, car no hi ha cosa que faci més fàstic que'l treure femta per la boca, ni vomitar sutzures devant la gent culta. El català que no vulgui tenir condícia del seu parlar, no hauria d'ésser admès enmig de la societat. Un home així, si vivia en societat, ens obligaria a tapar-nos el nas, i de tenir sempre a punt els bombers que netegin les immundícies que deixa per tot arreu, on va. CTILC - Lletres catalanes, Vilar i Costa, Joan (1946).

\subsection{CONVENCIONALITZACIÓ}

En els anteriors exemples, veiem situacions on la interpretació de l'expressió depenia del context. En els fragments següents veurem que el nou significat ja s'ha convencionalitzat i que forma part, per tant, de la semàntica de la locució ${ }^{\text {. Ja no cal }}$ que la corrupció o la pudor apareguen en l'entorn de tapar-se el nas, perquè ja en són trets constitutius:

${ }^{8}$ Com postula Levinson (2004, p. 263) i, seguint la seua teoria, Timofeeva (2012, 2016), les implicatures (o inferències) pragmàtiques acaben encastades en la representació semàntica i causen una intrusió de la pragmàtica. 
bens del comú, ipots pensar si li va gras! —No 'm fassis tapar lo nas... Y... ¿justament viu... d'alló? — ¡Vegessis com fa '1 senyó! CTILC - En Patufet, 3, Barcelona, 1904.

Una vegada han completat tot el procés de fraseologització, les locucions segueixen formant part de la llengua i, per tant, estan vives i poden seguir canviant. En aquest sentit, s'aprecia l'adopció de nous matisos en els exemples que presentem en l'apartat següent.

\subsection{CANVI FRASEOLÒGIC}

La utilització de les locucions provoca que conquerisquen nous usos, com els que veurem a continuació. Resulta interessant constatar que, com que s'ha esborrat la imatge inicial de corrupció i pudor, el fàstic deixa pas a sensacions menys intenses com ara el desencant i la decepció:

Els polítics em tenen molt desencantada i feia temps que no anava a votar, però aquesta vegada hi aniré perquè no vull el senyor Mas. Tot i que hi aniré amb el nas tapat", comenta Mercè Moreno, botiguera. Diari de Girona, Carles Colomer (18/11/2010).

Tinc un bon grapat d'amics que no votaven. Se sentien decebuts de totes les opcions d'esquerra i ja no feien cas de les coses que els déiem: 'tapeu-se el nas i voteu l'opció que us resulta més bona o menys dolenta. Levante, Salvador Vendrell (31/03/2019).

\section{SÍNTESI I PERSPECTIVA SINCRÒNICA}

\begin{tabular}{|c|c|c|c|}
\hline $\begin{array}{r}\text { Acció: Posar el polze } \\
\text { i l'índex sobre el nas } \\
\text { de manera que } \\
\text { tapen les narius }\end{array}$ & $\begin{array}{r}\text { Valor cultural: } \\
\text { reacció habitual a } \\
\text { una olor } \\
\text { desagradable }\end{array}$ & $\begin{array}{r}\text { Valor cultural II: } \\
\text { fàstic }\end{array}$ & $\begin{array}{r}\text { Valor cultural III: } \\
\text { decepció }\end{array}$ \\
\hline & $\begin{array}{l}\text { Enunciat: Tapar-se el } \\
\text { nas }\end{array}$ & & \\
\hline Codificació de l'acció & $\begin{array}{r}\text { Codificació del valor } \\
\text { cultural }\end{array}$ & $\begin{array}{r}\text { Codificació del valor } \\
\text { cultural II }\end{array}$ & $\begin{array}{r}\text { Codificació del valor } \\
\text { cultural III }\end{array}$ \\
\hline
\end{tabular}

Fig. 1. Esquema de les capes semiòtiques de l'enunciat tapar-se el nas segons el model de Burger (2010, p. 64) 
En l'actualitat tapar-se el nas és una cadena de mots que transmet quatre significats diferents: l'acció de tapar-se el nas, l'acció de tapar-se el nas a causa d'una olor desagradable, fàstic i decepció. De tots aquests significats, el primer seria composicional i la resta serien fraseològics. Com més s'allunyen (en el significat i en la figura) de l'acció fàctica, més idiomàtics es consideraran, és a dir, presentaran més informació contextual convencionalitzada. Segons els criteris de Burger (2010, p. 65), compliria les condicions per a ser un somatisme, perquè codifica una acció, al mateix temps que codifica el seu valor cultural. En teoria, l'acció a què remet encara és viva, ja que una persona pot tapar-se el nas. El que ja no està vigent és la imatge que va crear els valors culturals II i III. No és probable que una persona actual pense en la pudor generada per la corrupció d'un cos quan escolta l'expressió o la fa servir. En part, açò està causat pel canvi en la manera de conviure amb la mort i pels ritus funeraris asèptics actuals, que han provocat una modificació en el nostre esquema d'imatge referent al final de la vida. Convé remarcar que, malgrat la pèrdua de la imatge, part del contingut continua viu en els valors II i III.

A pesar que molts parlants actuals no l'analitzarien com a tal, es tracta d'una expressió polisèmica, els significats de la qual varien gradualment. En alguns casos, és difícil distingir entre un d'ells i l'anterior. Pel que fa a la codificació de l'acció fàctica, hi ha algunes pautes contextuals que ens orienten cap a ella, és a dir, cap al significat composicional.

Com a primera pauta, hi ha el fet que expliciten l'objecte amb què algú es tapa el nas. Per exemple, un mocador o la mà esquerra, com podem llegir en els fragments següents:

III Estornudar sense tapar-me el nas i la boca amb el mocador. CTILC - Salut. Higiene i educació física, Ramon Fagella (1935).

Es tapava el nas amb un mocador tenyit de sang. CTILC - La ciutat i el tròpic, Lluís Ferran de Pol (1956).

—No podries deixar sa porta oberta? — pregunta el capellà-. Això put! —afegeix mig tapant-se el nas amb la mà esquerra. CTILC - Dins el darrer blau, Carme Riera (1994).

Una altra pauta és que tapar-se el nas vaja associat amb menjar o beure. En aquest cas, la interpretació estarà orientada cap a menjar o beure alguna cosa amb gust desagradable i la intenció de no sentir-lo:

Perquè jo no vaig ser mai allò que se'n diu delicadet, com altres germans meus, els quals s'havia d'envestir amb la cullera i l'ampolla de l'oli de fetge de bacallà. Jo en aquest sentit no vaig donar maldecaps a la família, i les meves úniques despeses d'apotecari consistien en un bolado de citrat de magnèsia, que aleshores costava divuit cèntims. Me'l feien beure tapant-me el nas; em produïa la revolució intestinal exigida, i l'endemà ja m'havia passat tot i em tornava a trobar en condicions d'atipar-me del que fos. CTILC - Memòries, Josep M. de Sagarra (1954). 


\section{CONCLUSIONS}

La lingüística basada en l'ús, la perspectiva diacrònica i la metodologia de la lingüística de corpus ens forneixen amb el marc teòric i metodològic per a observar la construcció discursiva i cultural del significat. En el cas de les locucions, ens permeten veure la seua gènesi i evolució $i$, per tant, retre compte del fenomen de la idiomaticitat, el sorgiment del significat fraseològic.

Les locucions somàtiques són ideals per a aquesta mena d'anàlisi, per la seua gran freqüència, així com per la relació entre significat composicional i significat fraseològic que se'ls ha atribuit tradicionalment. Alguns autors les han qualificades com a transparents, altres com ara Burger hi han vist un potencial semiòtic analitzable en diverses capes. Les nostres observacions indiquen que la percepció de transparència prové del fet que siguen fàcilment motivables i que el potencial semiòtic és provocat per la polisèmia que adquireixen durant el procés de fraseologització.

En el cas de les locucions somàtiques, aquest procés transcorre de la manera següent. En primera instància, trobem una combinació lliure de paraules que codifica una acció, gest o tret humà. Aquesta codificació gaudeix d'especial importància, per la freqüència i prototipicitat, de forma que els seus components queden lligats entre si (significat holístic). L'acció o el seu valor social poden variar al llarg del temps, fet que provocarà que la relació amb l'enunciat no es reconega en un tall sincrònic posterior. Quan no es puga resseguir la relació, la disparitat entre el sentit composicional $\mathrm{i}$ el fraseològic es percebrà com a idiomaticitat. Fins i tot en les locucions somàtiques que presenten un significat fàcilment motivable, com ara tapar-se el nas, trobem elements contextuals del passat que s'han inserit en la semàntica actual de la locució i sense els quals no podríem explicar-ne la fixació.

La descripció d'aquest procés aporta nova informació sobre la natura lingüística del "valor social atribuït a l'acció", que es relaciona directament amb els valors inferencials lligats al context que es convencionalitzen per crear un significat nou. En aquest sentit, en cada tall sincrònic, una locució somàtica codificaria: una acció fàctica rellevant del passat, les implicatures (inferències) conversacionals associades amb l'enunciat i l'acció, l'enunciat lingüístic, la denominació de l'acció fàctica (com es formulava en l'època quan es va fixar) i les implicatures conversacionals convencionalitzades. En el cas que la locució haja estat remotivada, també codificaria el nou significat procedent de la nova motivació.

\section{AGRAÏMENTS}

Aquest estudi s'ha dut a terme en l'Institut Superior d'Investigació Cooperativa IVITRA [ISIC-IVITRA] (Programa per a la Constitució i Acreditació d'Instituts Superiors d'Investigació Cooperativa d'Excel-lència de la Generalitat Valenciana, 
Ref. ISIC/012/042), i en el marc dels projectes, xarxes i grups de recerca següents: «Variación y cambio lingüístico en catalán. Una aproximación diacrónica según la Lingüística de Corpus» (MICINUN, Ref. PGC2018-099399-B-100371); (IEC, Ref. PRO2018-S04-MARTINES); del Grup d'Investigació VIGROB-125 de la UA; la Xarxa de recerca en innovació en docència universitària «Lingüística de Corpus i Mediterrània intercultural: investigació educativa per a l'aplicació de la Lingüística de Corpus en entorns multilingües diacrònics. Aplicacions del Metacorpus CIMTAC» (Institut de Ciències de l'Educació de la UA, Ref. 4581-2018); i el Grup d'Investigació en Tecnologia Educativa en Història de la Cultura, Diacronia lingüística i Traducció (Universitat d'Alacant, Ref. GITE-09009-UA]). 


\section{REFERÈNCIES BIBLIOGRÀFIQUES}

Burger, H. (1998). Phraseologie. Eine Einführung am Beispeil des Deutschen (1a ed.). Berlín: Erich Schmidt Verlag.

Burger, H. (2010). Phraseologie. Eine Einführung am Beispeil des Deutschen (4a ed.). Berlín: Erich Schmidt Verlag.

Clark, A. (2008). Supersizing the mind: embodiment, action, and cognitive extension. Nova York: Oxford University Press.

Conca, M. \& Guia, J. (2014). La fraseologia. Principis, mètode i aplicacions. Alzira: Bromera \& IIFV.

Corpas, G. (1996). Manual de fraseología española. Madrid: Gredos.

Fillmore, C. J. (1985). Frames and the Semantics of understanding. Quaderni di Semantica, 6, 222-245.

García-Page, M. (2008). Introducción a la fraseología española: estudio de las locuciones. Rubí: Anthropos.

Heine, B. \& Kuteva, T. (2002). World Lexicon of Grammaticalization. Cambridge: Cambridge University Press.

Institut d'Estudis Catalans (2019). Diccionari de la llengua catalana. Barcelona: IEC. Recuperat de https://dlc.iec.cat/.

Lakoff, G. (1987). Women, fire, and dangerous things. What categories reveal about the mind. Chicago: University of Chicago Press.

Lakoff, G. \& Johnson, M. (1999). Philosophy in the Flesh: The Embodied Mind and its Challenge to Western Thought. Nova York: Basic Books.

Langacker, R. W. (1991). Foundations of Cognitive Grammar. Vol. II. Descriptive Application. Stanford: Stanford University Press.

Levinson, S. (2004). Significados presumibles: la teoría de la implicatura conversacional generalizada. Madrid: Gredos [Publicat originalment el 2000].

Martines, J. (2020). Cap a una semàntica cognitiva del català (I): La cognició, el cos, l'espai i el temps. Estudis Romànics [Institut d'Estudis Catalans], 42, 323-343. DOI: 10.2436/20.2500.01.302

Martines, J. (2021). Cap a una semàntica cognitiva del català (i II): La cognició, el cos i la cultura. Estudis Romànics [Institut d'Estudis Catalans], 43, 267-301. DOI: 10.2436/20.2500.01.319

Martines, J., Martines, V. \& Pérez-Saldanya, M. (dir.). Corpus Informatitzat de la Gramàtica del Català Antic [CIGCA]. Alacant: ISIC-IVITRA(Universitat d'Alacant). Recuperat de http://www.ivitra.ua.es.

Martines, J., Martines, V. \& Pérez-Saldanya, M. (dir.). Corpus Informatitzat de la Gramàtica del Català Modern [CIGCAMod]. Alacant: ISIC-IVITRA (Universitat d'Alacant). Recuperat de http://www. ivitra.ua.es.

Piirainen, E. (2012). Widespread Idioms in Europe and Beyond. Toward a Lexicon of Common Figurative Units. Nova York: Peter Lang.

Rafel i Fontanals, J. (dir.). Corpus Textual Informatitzat de la Llengua Catalana (CTILC). Barcelona: Institut d'Estudis Catalans. Recuperat de https://ctilc.iec.cat/.

Rubert, R. (2009). Cognitive Systems and the Extended Mind. Nova York: Oxford University Press.

Ruiz Gurillo, L. (1997). Aspectos de fraseología teórica española. València: Universitat de València.

Sánchez-López, E. (2015). Phraseologization as a process of semantic change. Catalan Journal of Linguistics, 14, 159-177. DOI: 10.5565/rev/catjl.168

Sánchez-López, E. (2020). On the importance of a diachronic approach to phraseology. Dins J. Fernández \& H. Provencio (eds.), Changes in Meaning and Function: Studies in historical linguistics with a focus on Spanish (p. 300-329). IVITRA Research in Linguistics and Literature, 25. Àmsterdam: John Benjamins.

Sánchez-López, E. (en premsa). La elaboración discursiva de los somatismos. eHumanista. Journal of Iberian Studies. 
Shapiro, L. (2011). Embodied Cognition. Nova York: Routledge.

Timofeeva, L. (2012). El significado fraseológico. En torno a un modelo explicativo y aplicado. Madrid: Liceus.

Timofeeva, L. (2016). Locuciones. Dins J. Gutiérrez-Rexach, Enciclopedia de Lingüística Hispánica. Nova York: Routledge.

Traugott, E. C. \& Dasher, R. B. (2002). Regularity in Semantic Change. Cambridge: Cambridge University Press. 